Article

\title{
Air Pollution Assessment via Statistical Reasoning, and its Implications: A Case Study of Baekryeong Island in Republic of Korea
}

\author{
Seok Ho Chang ${ }^{1}$ and Soonhui Lee ${ }^{2, *}$ \\ 1 College of Business, Hankuk University of Foreign Studies, Republic of Korea; seokhochangaaa@gmail.com \\ 2 College of Business, Hankuk University of Foreign Studies, Republic of Korea, soonhui.lee@gmail.com \\ shlee2016@hufs.ac.kr \\ * Correspondence: soonhui.lee@gmail.com Tel.: +82-2-2173-3177
}

\begin{abstract}
The frequency and intensity of air pollution are two of most critical issues the world faces in dealing with global environmental problems. They are both important areas that need to be improved. Our previous research [20] examines the assessment of fine dust pollution in Baekryeong island by statistical reasoning through one specific example of inland city (Yanggu) in Republic of Korea; however, given that Baekryeong Island is a remote island, there has been little focus on in-depth examination of its effect on the high density of fine dust in Baekryeong Island. The purpose of this article is twofold: (i) to examine the effect of a remote island on the high density of fine dust on Baekryeong Island using statistical reasoning and to provide a more specific statistical basis for the claim that one of the non-negligible factors influencing the high density of fine dust on Baekryeong Island is the geographic proximity to China; and (ii) to present brief discussion of fundamental cause of fine dust and global air pollution issues, which are not discussed in [20].
\end{abstract}

Keywords: fine dust pollution; ozone layer and climate change; global environmental problems, statistical reasoning, air pollution assessment, desertification, particulate matter (PM)

\section{Introduction}

The international journal Nature in 2017 reported that the ultrafine dust emitted from China could harm the health of people around the world. It suggested that 7 million people died worldwide each year due to fine dust in the spring [1]. According to that paper [1], atmospheric particulate matter (PM) with diameter of less than $2.5 \mu \mathrm{m}$ can move across the country and other countries, such as China, leading to premature death. China has the greatest number of early deaths due to fine dust (1.9 million deaths), followed by India (580,000 deaths), Southeast Asia (450,000 death), the Middle East and North Africa (280,000 deaths), Eastern Europe (220,000 deaths), and Western Europe (200,000 deaths) [1]. Other East Asian countries including Republic of Korea, Mongolia, North Korea and Japan have about 89,000 deaths due to fine dust. Analysis shows that $90 \%$ of premature deaths from cardiovascular diseases are due to ultrafine dusts designated as carcinogens [1].

According to a report [2] by Financial Times in the UK in 2017, Republic of Korea has joined the ranks of the world's most polluted countries, with air pollution in the first months of 2017 soaring to record levels. Long associated with Asian capitals such as Beijing or Delhi, hazardous smog has for weeks blanketed Seoul - a city now appearing among the world's three most polluted in daily rankings [2]. 
In June 2016, the Organization for Economic Cooperation and Development (OECD) warned serious air pollution problems in Republic of Korea surrounded by fine dust and called for aggressive responses [3]. The OECD published a report on the economic consequences of outdoor air pollution, and calculated the social costs associated with increased particulate and surface ozone [3]. Among neighboring countries of China, Republic of Korea and Japan accounted for half $(39,900)$ of total deaths $(89,000)$ due to fine dust. The analysis shows that $90 \%$ of premature deaths from cardiovascular diseases are due to ultrafine dusts designated as carcinogens [3].

According to a recent report on the smog in the Seoul area, China's Xinhua news agency mentions that the cause of the smog that sometimes appears in Seoul is caused by the basin terrain, population density, large diesel cars, enormous quantities of dust and vehicles. It does not rule out the effects of smog from neighboring country [4].

In recent years, Republic of Korea's air pollution has become one of major social issues [5,6]: On March 26-27 and April 6, 2018, Seoul reported that it had the highest level of fine dust in the world. PM2.5 warning has been issued four times already during the first half of 2018 [6-8]. Ultrafine dust warning is issued when the average concentration per hour is over $90 \mu \mathrm{g} / \mathrm{m}^{3}$ for 2 hours [6]. According to the Ministry of Environment of the Republic of Korea, smog formation from China is getting worse and the period of occurrence is shortened. Although domestic pollutant emissions are reduced, high concentration fine dust is not decreasing [6]. According to the report of the Gyeonggi Provincial Health and Environment Research Institute in Republic of Korea on April 10, 2018, there have been 42 cases of PM10 and PM2.5 warnings, with warnings for 16 days in four regions in the province. The average concentration and duration of announcement at the time of warning were worse this year (2018) than last year (2017) [6].

The National Institute of Environmental Research (NIER) in Republic of Korea divides the causes of fine dust into domestic emissions and external influences [6]. According to the research report in NIER, the ratio of impacts at home and abroad differs from researcher to researcher, but it is usually $40 \sim 70 \%$ [6]. Domestic emissions are caused by economic activities such as energy consumption in daily life, automobile operation and industrial activities. In the case of the metropolitan area, automobiles and large-scale business sites nationwide are the largest sources. Domestic influences are big. However, the impact from abroad sometimes can be up to $70 \%$. Thus, the influence of China cannot be ignored. NIER also announced the contribution rate analysis for fine dust. The amount of fine dust coming from outside the country varies by season and case. In 2016, the NIER and the NASA conducted three-dimensional observations on three aircraft, 18 NASA ground survey sites, and 6 satellites, including NASA's research aircraft, through a joint study of the Korean peninsula in spring [9-12]. As a result, it was found that the foreign influence was $48 \%$ and the domestic emission was $52 \%$. Among foreign influences, the influence of China was $34 \%$, with the influence of the Shandong Peninsula region adjacent to our country accounting for $22 \%$ [9-12]. Although China reported a significant improvement in air quality over the past few years due to its harsh smog warfare policy, many scientists, journals and press releases have pointed to the fine dust effects of China. However, China has not acknowledged that.

At the same time, it is reported that the number of domestic ozone $\left(\mathrm{O}_{3}\right)$ warning messages in Republic of Korea has been continuously increasing [13]. Human health threat posed by invisible ozone can no longer be overlooked [13-14]. According to the Ministry of Environment's air quality database 'Air Korea [14]' in Republic of Korea provided on February 27, 2018, the number of ozone warning messages issued nationwide was only 64 in 2012. It was increased to 276 in 2017, more than 4.3 times in five years [13]. In addition, summer heatwave has become one of major social issues in Republic of Korea: In mid-July 2018, the average temperatures in Seoul and Daegu in Republic of Korea are 30.7 and 35.1 degrees, respectively [15-16]. It was the highest in 24 years since 1994. According to Center for Disease Control and Prevention in Republic of Korea, there were 2,549 patients with hyperthermia (30 deaths) during the period from May 20 to May 2 this year (2018). Last summer (2017), total number of patients with hyperthermia was 975 [15-16].

Baekryeong Island is an island of Republic of Korea. It is the largest island of the five islands in the west of the 5th degree [17]. It is $149 \mathrm{~km}$ from Pyongyang in North Korea, and $225 \mathrm{~km}$ from 
Weihai in China. It has the shortest distance from the mainland of Shandong Peninsula [17]. The Marine Corps of the Republic of Korea (ROK) is stationed at the forefront of North Korea as a military base [17]. It has been reported that the fine dust concentration in Baekryeong Island is close to that in Seoul [17-18]. Accordingly, there are articles and news claiming that China's overseas dust particles have significant effect on the high density of fine dust in Baekryeong Island considering that the pollution level of Baekryeong Island, which has lower levels of population and vehicles densities compared to those of Seoul, is close to that of Seoul [17-19]. On the other hand, some argue that that high density of fine dust in Baekryeong Island are due to factors such as pollutants emitted from the forefront military bases and the influence of North Korea which is geographically close to the North [17-19].

Previous research [20] has assessed the fine dust pollution in Baekryeong island by statistical reasoning through one specific example of inland city (Yanggu) in Republic of Korea. However, given that Baekryeong Island is a remote island, there has been little focus on in-depth examination of the effect of a remote island on the high density of fine dust in Baekryeong Island.

The purpose of this article is twofold: (i) to examine the effect of a remote island on the high density of fine dust on Baekryeong Island using statistical reasoning and to provide a more specific statistical basis for the claim that one of the non-negligible factors influencing the high density of fine dust on Baekryeong Island is the geographic proximity to China; and (ii) to present brief discussion of fundamental cause of fine dust and global air pollution issues not discussed in [20].

In this article, we present a series of statistical reasonings that leads to a rational conclusion from hypothesis setting and data. It is advantageous in that it is much more time- and cost- effective to validate the result, especially when there is time and budget limitation as opposed to methodology used in joint research of NIER and NASA.

The statistical analysis presented in this article provides a statistical basis for the claim that geographically proximity to China is one of the nonneglected factors influencing high density of fine dust in Baekryeong Island. This finding supports result of joint research of NIER and NASA that the neighboring country is one of the major external factors for the occurrence of the air pollution in Republic of Korea.

The rest of this article is organized as follows: In Section 2, this article briefly presents the definition and severity of fine dust, ozone, and global warming, issues associated with global environmental problems. In Section 3, this article provides a more specific statistical basis for the claim that one of the nonnegligible factors influencing the high density of fine dust in Baekryeong Island is the geographically proximity to China. Section 4, this article presents the implications of results, including some comments on the fundamental cause of fine dust, global air pollution issues (such as ozone, desertification, and global warming, sustainable energy), and subsequent international cooperation of global air pollution.

\section{Definitions and Severity of fine dust, ozone and global warming}

This section briefly presents the definition and severity of fine dust, ozone, and global warming, all of which are issues associated with global environmental problems.

\subsection{Particulate Matter (PM) [21]}

Dust is divided into total dust, minute dust (PM 10) with diameter less than $10 \mu \mathrm{m}$, and ultrafine dust with diameter less than $2.5 \mu \mathrm{m}$ (PM 2.5) depending on particle size. When people are exposed to fine dust for a long time, their immunity is rapidly lowered, making them susceptible to various diseases, including cardiovascular diseases, skin diseases, eye diseases, and respiratory diseases such as colds, asthma and bronchitis [21]. Ultrafine dust having a diameter of less than 2.5 
$\mu \mathrm{m}$ can particularly penetrate into the bronchi and deep into lungs of the human body [21]. Its heavy metal content is high enough to be called as fine heavy metal rather than fine dust [21]

In Republic of Korea, the atmosphere is often smog with a lot of fine dust and other air pollutants coming from China. Particularly troublesome is that dust has a seasonal limitation. Fine dust can occur when the wind blows in the direction of Korea. Given that China is the country with the largest amount of fine dust, there are factors that cause damage to its neighboring countries such as Republic of Korea and Japan. In addition, there are factors that cause damage to its neighboring countries such as the Republic of India, Pakistan, Bangladesh, Iran, Afghanistan, northern Vietnam, and the Arabian Peninsula and Sahara Desert [21]. Karagulian et al. [23] provided a literature review on particulate matter (PM). Sternberg and Mona Edwards [22] have reviewed desert dust and health. Literature on PM can be found from literature listed of [21,23]

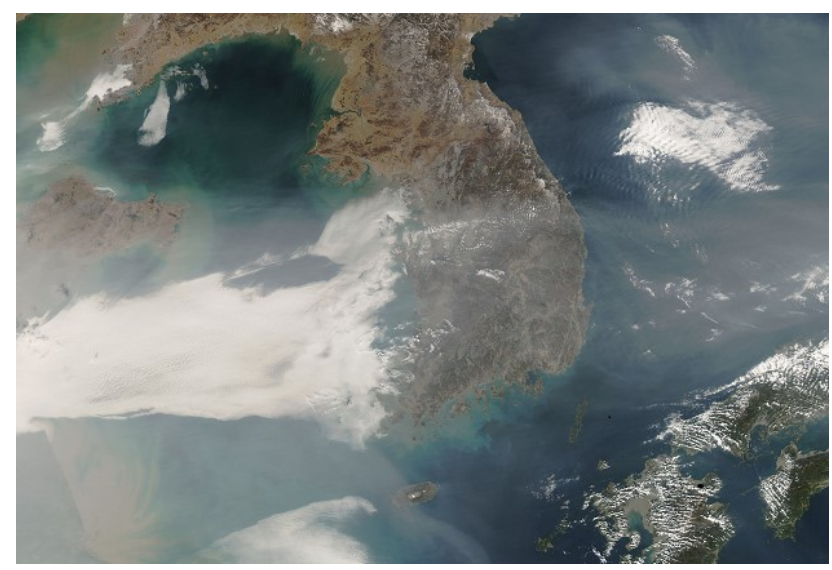

Figure 1. NASA satellite image shows a swath of air pollution sweeping east across the Korean peninsula to Japan [24]

\subsection{Ozone (оз) [25]}

Ozone is a colorless gas derived from the Greek 'ozein' which means 'smell'. It is a gas with strong oxidizing power and high energy. High concentration of ozone is harmful to the human body. When it occurs, ozone alarm is issued in Republic of Korea. There are three kinds of ozone alarm: 1 ) Caution, when ozone concentration 0,12 ppm or more; 2) Alarm, when ozone concentration 0.3ppm or more; and 3) Critical alarm, when ozone concentration 0.5 ppm or more

High concentration ozone is mainly observed in the summer due to high temperature and high radiation dose. Recently, ozone warning is continuing from spring to autumn. This indicates that, while the average temperature on the surface of the earth continues to rise due to global warming, emissions of pollutants are also increasing. Ozone is an air pollutant. It is a greenhouse gas that can accelerate global warming which generates more ozone at the surface, leading to a vicious cycle. Ozone also has strong oxidizing power. It is involved in the production of ultrafine dust (PM2.5) [21].

When ozone concentration is high, respiratory and lung function of a person will deteriorate. High ozone concentration can exacerbate symptoms such as eye and neck sting, airway constriction, dyspnea, headache, cough, nausea, bronchitis, heart disease, emphysema and asthma [25]. Elderly people and children with weak respiratory or pulmonary functions should be especially careful. They should not go out or exercise if there is ozone notice or warning. It is best to stay indoors as much as possible because indoor ozone is reduced by $30 \sim 50 \%$ compared to outdoor. It is important to reduce the use of cars when ozone concentration is high. The elderly should refrain from going 
out and children should stop outdoor physical activities at school when ozone concentration is high. In addition, high ozone concentration can be fatal to people with respiratory or cardiac conditions. Healthy people should keep in mind that ozone penetrates deep into the lungs and causes harm to the human body if they are exposed to ozone warnings. For literature review on ozone and its severity, see literature listed in [25].

\subsection{Global warming (Climate Change) [26-27]}

Global warming is also referred to as climate change. It is the observed century-scale rise in the average temperature of the earth's climate system and its related effects [26-27]. Damage caused by global warming can be noticeably seen in animal habitat migration due to the continuous rise in temperature since the early 20th century. Habitat of animals such as squirrels and mice are moving further north. In addition to animal habitat, the disappearance of Arctic lakes is also an evidence that global warming is serious. Over the past few decades, 125 large northern giant lakes have disappeared. Tuvalu is the first country to suffer from global warming. Part of the country has been flooded due to rising sea level caused by global warming. The Tuvalu government has officially abandoned the country. The summit of the Himalayas has an enormous amount of water resources called the Earth's water tanks. People in Nepal, India, China and other neighboring countries of the Himalayas are living on this water using the melted water. However, this water is disappearing at a rapid pace due to global warming. Mecca (a desert valley in western Saudi Arabia) and the Maldives (a tropical nation in the Indian Ocean) are also examples of global warming damage. In fact, countries with coast have direct and indirect damages caused by global warming. The Maldives, like Tuvalu, has retreating coastline and reducing the size of its land. As a result, tourism, the largest industry in the Maldives, is being reduced.

In 2015, the Ministry of Environment and the Korea Meteorological Agency published a report on the scientific basis and impact of climate change in Republic of Korea [27-28]. The Korea Climate Change Assessment Report 2014 is a compilation of 2,500 research results from 2010 to 2014. According to the Korea Climate Change Assessment Report 2014, the annual average temperature and sea level rise patterns are observed in Republic of Korea. An increase in anthropogenic greenhouse gases has been found to be a major cause. Average annual temperature of Korea has increased from $0.25{ }^{\circ} \mathrm{C} / 10$ years from 1954 to $1999,0.41{ }^{\circ} \mathrm{C} / 10$ years from 1981 to 2010 and $0.5{ }^{\circ} \mathrm{C}$ / 10 years from 2001 to 2010. Average annual temperature of the Korean peninsula has risen sharply since the 1980s. Researchers has evaluated that the warming of the Korean peninsula has a significant impact on the warming of the greenhouse gases that cause warming in Asia and East Asia. It has been predicted that health damage caused by heat will increase in the future due to rising temperature. According to the Korea Climate Change Assessment Report 2014, deaths from heatwaves in Seoul will increase by more than twice (from 0.7 per 100,000 during 2001-2010 to 1.5 per 100,000 population during 2036 to 2040). For literature review on global warming, see literature listed in [25-26].

\section{Statistical Reasoning and Analysis}

This section provides a concise and precise description of the experimental results, their interpretation as well as the experimental conclusions that can be drawn.

\subsection{Known statistics}

According to atmospheric environment of Republic of Korea, it is reported that average density of fine dust in Baekryeong Island is close to that in Seoul [27]. 


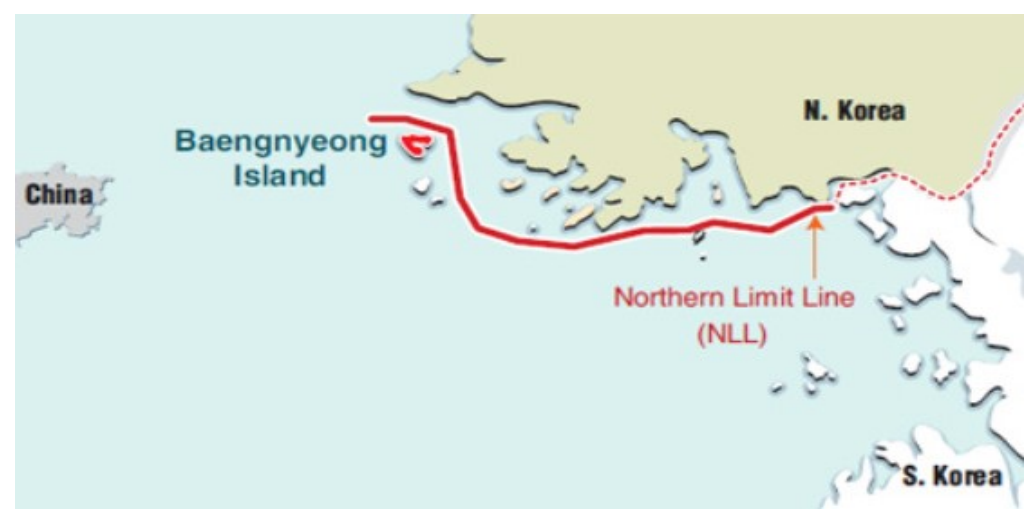

Figure 1. Location of Baekryeong Island (Baekryeong-do)

Table 1. Average densities of fine dust in Seoul and Baekryeongdo (Jan 2015-June 2016)

\begin{tabular}{|l|l|l|}
\hline & Seoul & Baekryeong Island \\
\hline PM10 & $47.72 \mu \mathrm{g} / \mathrm{m}^{3}$ & $47.88 \mu \mathrm{g} / \mathrm{m}^{3}$ \\
\hline PM2.5 & $23.77 \mu \mathrm{g} / \mathrm{m}^{3}$ & $23.71 \mu \mathrm{g} / \mathrm{m}^{3}$ \\
\hline
\end{tabular}

Table 2. Population and area of Seoul and Baekryeongdo (December 2017)

\begin{tabular}{|l|l|l|}
\hline & Seoul & Baekryeong Island \\
\hline Population & 9891,448 persons & 5,721 persons \\
\hline Area & $605.2 \mathrm{~km}^{2}$ & $51 \mathrm{~km}^{2}$ \\
\hline
\end{tabular}

Besides, vehicles density in Baekryeong Island is much lower than that in Seoul [17]. Accordingly, there are articles and news claiming that China's overseas dust particles have significant effect on high density of fine dust in Baekryeong Island considering that air pollution level of Baekryeong Island, (which has lower levels of population and vehicles densities compared to those of Seoul), is close to that of Seoul [17-19]. On the other hand, some argue that that high density of fine dust in Baekryeong Island are due to factors such as pollutants emitted from the forefront military bases and the influence of North Korea, which is geographically close to the North [17-19].

\subsection{Statistical reasoning and assumptions}

This article approaches the issue of high density of fine dust in Baekryeongdo, the value of which is close to that of Seoul, based on a series of statistical reasonings:

Although, the fine dust emitted from China (or the geographically proximity to China) is suspected to be one of the main factors that affect the high density of fine dust in Baekryeongdo, we tentatively do not include the geographically proximity to China in the list of main factors that affect the high density of fine dust index in Baekryeongdo. Thus, we have the following assumption 1. 
Assumption 1: Factors affecting the high density of fine dust in Baekryeongdo are assumed to be (i) the influence of geographically adjacent North Korea, (ii) the substances emitted from the foremost military units, which are the main factors suggested in the counter-argument. We assume that the geographically proximity to China does not affect the high value of fine dust index in Baekryeongdo significantly.

Since it is difficult to directly obtain data or quantify the factors that indicate the influence of geographically adjacent North Korea and the substances emitted from the forefront military bases of Baekryeongdo, we take an alternative approach:

We select Ulreung Island [28], a specific region in Republic of Korea that satisfy assumption 1 closely. The environment of Ulreoung Island is very similar to that of Baekryeongdo. It is geographically distant from China, thus satisfying assumption 1 approximately.

\section{- Ulreoung Island (Ulreoung-do) [28]}

Ullreung Island (sometimes called Ulreoung-do) is one of the islands in Republic of Korea. It is 120kim (75 mi) east of Korean Peninsula. It is one of the forefront areas that border South Korea with North Korea. In addition, it is geographically distant from China, thus satisfying assumption 1 approximately. In Ulreoung-do, there is Naval 118th Early Alert Squadron in the forefront. It is a guarding and book defending unit of the Navy 1st Fleet. It is responsible for defense of Ulreung-do. It performs maritime surveillance mission of the whole East Sea. Ulleungdo has a lower population density and fewer vehicles compared to Seoul [28]. Therefore, main factors affecting the fine dust index in this region are expected to be the factors such as the elements of the forefront military bases or North Korea due to the characteristics of the forefront. Ulreoung-do is a typical example of a remote island. Its environment of which is very similar to that of Baekryeongdo.

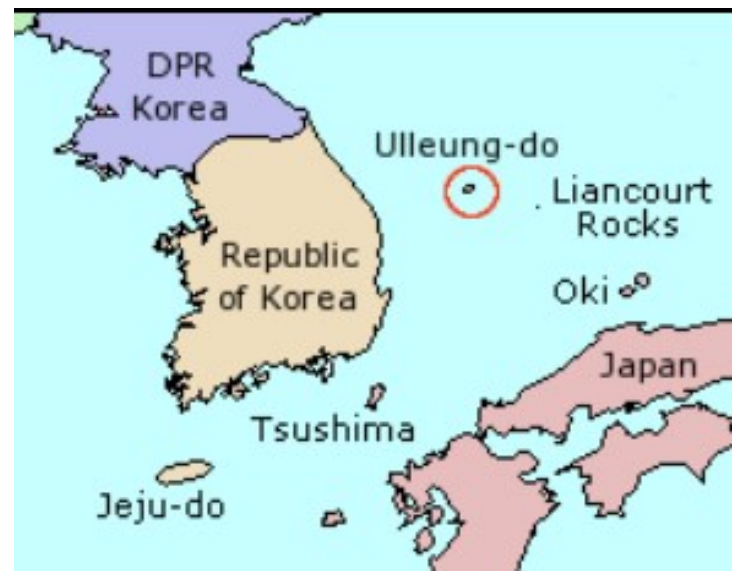

Figure 2. Location of Ullreung-do [28]

Table 3. Population and area of Baekryeongdo and Ulreoung-do (December 2017)

\begin{tabular}{|l|l|l|}
\hline & Baekryeong Island & Ulreoung Island \\
\hline Population & 5,721 Persons & 9,975 Persons \\
\hline Area & $51 \mathrm{~m}^{2}$ & $72.52 \mathrm{~m}^{2}$ \\
\hline
\end{tabular}

We now make the following assumption 2: 
Assumption 2: Factors affecting the values of fine dust concentration in Ulreung-do is assumed to be: (i) the influence of geographically adjacent North Korea, (ii) the substances emitted from the foremost military units as main factors suggested in the counter-argument.

Under the assumptions 1 and 2, the following hypothesis are set for the fine dust index in Ulreoung-do:

$\mathrm{H}_{0}$ (Null hypothesis): Average density of fine dust in Ulreung-do = average density of fine dust in Seoul.

$\mathrm{H}_{1}$ (Alternative hypothesis): Factors of the nearest military bases in Ulreung-do and neighboring North Korea do not have significant effect on the increase of the fine dust concentration of Ulreung-do to the level comparable to or exceeding Seoul 's fine dust index. That is, the value of fine dust concentration in Ulreung-do will be smaller than that in Seoul. (Average density of fine dust in Ulreung-do < average density of fine dust in Seoul)

Under the assumption that the null hypothesis is true, the average densities of fine dust in Seoul and Ulreung-do are compared between 2010 and 2017. Due to the limitation of space, we only present some of recent results (2016-2017) of average densities of fine dust in Seoul and Ulreoung-do (see appendix for details):

Table 4. Fine dust (PM10) Monthly air pollution (unit: $\mu \mathrm{g} / \mathrm{m}^{3}$ )

Seoul Ulreung-do

$\begin{array}{lll}\text { 2016 Jan } & 50 & 28 \\ \text { 2016 Feb } & 45 & 34 \\ \text { 2016 Mar } & 64 & 46 \\ \text { 2016 Apr } & 71 & 65 \\ \text { 2016 May } & 56 & 57 \\ \text { 2016 Jun } & 45 & 25 \\ \text { 2016 Jul } & 33 & 26 \\ \text { 2016 Aug } & 34 & 34 \\ \text { 2016 Sep } & 37 & 32 \\ \text { 2016 Oct } & 38 & 40 \\ \text { 2016 Nov } & 52 & 47 \\ \text { 2016 Dec } & 48 & 37 \\ \text { 2017 Jan } & 53 & 46 \\ \text { 2017 Feb } & 46 & 43 \\ \text { 2017 Mar } & 60 & 54 \\ \text { 2017 Apr } & 56 & 53 \\ \text { 2017 May } & 63 & 53 \\ \text { 2017 Jun } & 41 & 33 \\ \text { 2017 Jul } & 33 & 30 \\ \text { 2017 Aug } & 21 & 23 \\ \text { 2017 Sep } & 32 & 33\end{array}$


Remark 3.1> The above data was extracted from the Ministry of Environment, Air pollution status in Republic of Korea [29]

Remark 3-2> Statistical analysis was performed by extracting only the comparable year of each data.

Since each data pair and the number of data is 88 , a pairwise test was used to compare the differences between the two populations [30]. The following is the result of the pairwise comparison test (significant level of test $=0.01$ ) using Excel (2016):

Table 5. Results of $\mathrm{t}$ test, a pairwise comparison test

t-test results:

Pairwise comparison test

\begin{tabular}{lrr}
\hline & \multicolumn{1}{c}{ Seoul } & Ulreung-do \\
\hline Average & 45.43181818 & 39.03409091 \\
Sample variance & 176.776907 & 115.159744 \\
Number of & 88 & 88 \\
observations & & \\
Pearson's correlation & 0.659518153 & \\
coefficient & & \\
Difference between & & \\
two means & & \\
d.f. & & \\
t statistics & & \\
P(T<=t) one-sided & $3.51856 \mathrm{E}-08$ & \\
p-value & & \\
t statistics one-sided & 2.369976779 \\
P(T<=t) two-sided & $7.03712 \mathrm{E}-08$ \\
p-value & & \\
t statistics two-sided & 2.633527229 \\
\hline
\end{tabular}

As can be seen from the above table, the null hypothesis that the two population groups (Seoul and Ulreoung-do) have the same mean is true is rejected because the p-value is 0.0000000351856 , which is less than the significance level 0.01. In other words, the assertion of the alternative hypothesis that the concentration of fine dust of Ulreoung-do is less that of Seoul is statistically significant, and the reliability of this conclusion is 0.99 .

Remark 3-3> Similar statistical analysis was conducted for various inland regions (such as Ko-sung, Jeong-Sun, and Hoeng-Sung) in Republic of Korea with the forefront military bases, the environment of which are very similar to that of Baekryeongdo. All regions mentioned are geographically distant from China but geographically close to North Korea. They are also close to the forefront military bases, thus satisfying assumption 1 approximately. All of them have the same 
conclusions as those presented in this article. Due to the limit of space, we only present the results for Uleung-do.

\subsection{Main factor affecting the high density in Baekryong Island, and implications}

This article now goes back to our original question on the factors that have major impacts on the high density of fine dust of Baekryeongdo Island. The most important factors that influence the high density of fine dust of Baekryeongdo are suspected to be the factors influenced by the forefront military influence brought about by counterinsurgency and the geographically adjacent factors of North Korea.

Although it is not exactly geographically consistent with Baekryeong Island, some locations, such as Ulreoung Island, Ko-sung, Jeong-Sun, Hoeng-Sung, and Yang-gu have environments similar to Baekryeongdo (being geographically close to North Korea with the forefront military bases). Through these examples, we can see that factors such as (i) the influence of geographically adjacent North Korea, and (ii) the substances emitted from the foremost military units do not have a significant effect on the increase of the average density of fine dust of Ulreoung-do, Ko-sung, Jeong-Sun, Hoeng-Sung, and Yang-gu to levels comparable to or exceeding Seoul 's fine-dust index.

Now we apply above conclusion to the issue of high density of fine dust in Baekryeongdo. If our assumption 1 is true, there is not enough reason to expect the average density of fine dust in Baekryeongdo to be as high as that of Seoul. However, in reality, the average density of fine dust in Baekryeongdo is as high as that in Seoul. This means that our assumption 1 is not true. We also note that Ulreoung-do, Ko-sung, Jeong-Sun, Hoeng-Sung, and Yang-gu are farther away from China than Baekryeong Island (see Figure 4). Therefore, among the factors affecting the high density of fine dust in Baekryeongdo, the geographically proximity to China is one of nonnegligible factors that significantly affects high density of fine dust in Baekryeongdo.

\section{Discussion, conclusion, and implications}

The statistical analysis presented in this article provides a statistical basis for the claim that geographically proximity to China is one of the nonneglected factors influencing high density of fine dust in Baekryeong Island. This finding supports the result of joint research of NIER and NASA that the neighboring country is one of the major external factors for the occurrence of the air pollution in Republic of Korea. Note that joint research of NIER and NASA conduct three-dimensional observations on three aircraft, 18 NASA ground survey sites, and 6 satellites, including NASA's research aircraft, through a joint study, which is time-consuming and costly.

The research methodology presented in this article is rather involved in the sense that it is a series of statistical reasonings that needed to have a rational conclusion from hypothesis setting and data. Although joint research of NIER and NASA can produce very detailed and accurate results in evaluating the air pollution in Republic of Korea, our research methodology presented in this article has some advantages: (i) It is much more time- and cost- effective in evaluating the main factors that affect the air quality of a certain specific region when there is time and budget limitation. (ii) It can also be used to validate the results of time-consuming and costly methodologies.

Based on the methodology presented in this article, further research is required to study the factors for the occurrence of the air pollution in Asia including Republic of Korea, China, and Japan.

Fine dust, desertification, ozone layer and global warming, and destruction of ecosystem are associated with global environmental problems. Solving one problem does not mean that other problems are solved. Unlike developed countries where industrialization and urbanization have progressed gradually since the Industrial Revolution, developing countries that have undergone rapid economic growth, industrialization and rapid population growth are continuing to put more emphasis on economic development, Such fine dust issues will naturally occur when we focus on 
industries that developed countries are trying to avoid because of our relatively lack of awareness or when we deal with industrial waste from developed countries.

The world is a respiratory community. Air cannot be stopped at the border. In the end, the world must face its head to form a joint research team to identify the cause of the pollution and improve the air quality. It is necessary to identify and plan the management accordingly. While joint research and cooperation have made progress, much work remains to be done.

Some specific ways we could do to help to reduce global air pollution include the effort to prevent desertification [31][22], develop land in environmental friendly ways [32-33], reduce the use of disposables [32-33], make endeavor to have forests and trees [32-33], consider the use of sustainable energy [34], reduce greenhouse gases [35], reduce the amount of carbon dioxide emitted in daily life [39], and practice environment-friendly attitude [40-41].

Author Contributions: SH.C. designed the research with support from S.L.; SH.C present the methodology, analyze the data with support from S.L.; SH.C wrote the paper with additions and edits by S.L.

Acknowledgement: This research was supported by Hankuk University of Foreign Studies Research Fund

Conflict of Interest: The authors declare no conflict of interest.

Appendix A: Average densities of fine dust in Seoul and Ulreoung-do (2010-2017)

We present average densities of fine dust in Seoul and Ulreoung-do from 2010 to 2017:

Table A1. Fine dust (PM10) Monthly air pollution (unit: $\mu \mathrm{g} / \mathrm{m}^{3}$ )

Seoul

Ulreoung-do

2010 Jan

59

NA

$2010 \mathrm{Feb}$

50

37

2010 Mar

61

43

2010 Apr

49

50

2010 May

56

49

2010 Jun

51

50

$2010 \mathrm{Jul}$

33

45

2010 Aug

32

48

2010 Sep

25

39

2010 Oct

2010 Nov

71

55

2010 Dec

61

48

2011 Jan

44

33

2011 Feb

75

50

2011 Mar

65

58

2011 Apr

56

NA

2011 May

79

NA 


\begin{tabular}{|c|c|c|}
\hline 2011 Jun & 44 & NA \\
\hline $2011 \mathrm{Jul}$ & 28 & 25 \\
\hline 2011 Aug & 27 & 18 \\
\hline 2011 Sep & 29 & 23 \\
\hline 2011 Oct & 42 & 33 \\
\hline 2011 Nov & 37 & 33 \\
\hline $2011 \mathrm{Dec}$ & 46 & 29 \\
\hline 2012 Jan & 60 & 35 \\
\hline 2012 Feb & 50 & 38 \\
\hline 2012 Mar & 47 & 42 \\
\hline 2012 Apr & 51 & 50 \\
\hline 2012 May & 52 & 44 \\
\hline 2012 Jun & 40 & 32 \\
\hline $2012 \mathrm{Jul}$ & 28 & 36 \\
\hline 2012 Aug & 22 & 34 \\
\hline 2012 Sep & 27 & 30 \\
\hline 2012 Oct & 33 & 39 \\
\hline 2012 Nov & 42 & 39 \\
\hline 2012 Dec & 41 & 31 \\
\hline 2013 Jan & 64 & 45 \\
\hline 2013 Feb & 45 & 44 \\
\hline 2013 Mar & 55 & 57 \\
\hline 2013 Apr & 52 & 46 \\
\hline 2013 May & 56 & 64 \\
\hline 2013 Jun & 40 & 42 \\
\hline $2013 \mathrm{Jul}$ & 34 & 49 \\
\hline 2013 Aug & 35 & 51 \\
\hline 2013 Sep & 28 & 30 \\
\hline 2013 Oct & 29 & 30 \\
\hline 2013 Nov & 43 & 36 \\
\hline 2013 Dec & 55 & 32 \\
\hline 2014 Jan & 57 & 35 \\
\hline 2014 Feb & 57 & 37 \\
\hline 2014 Mar & 60 & 48 \\
\hline 2014 Apr & 58 & 52 \\
\hline 2014 May & 63 & 57 \\
\hline 2014 Jun & 38 & 32 \\
\hline $2014 \mathrm{Jul}$ & 38 & 30 \\
\hline 2014 Aug & 29 & 22 \\
\hline 2014 Sep & 29 & 21 \\
\hline 2014 Oct & 33 & 27 \\
\hline
\end{tabular}




\begin{tabular}{|c|c|c|}
\hline 2014 Nov & 45 & 28 \\
\hline 2014 Dec & 43 & 28 \\
\hline 2015 Jan & 49 & 29 \\
\hline 2015 Feb & 84 & 46 \\
\hline 2015 Mar & 71 & 50 \\
\hline 2015 Apr & 45 & 44 \\
\hline 2015 May & 45 & 43 \\
\hline 2015 Jun & 35 & 29 \\
\hline $2015 \mathrm{Jul}$ & 30 & 26 \\
\hline 2015 Aug & 34 & 39 \\
\hline 2015 Sep & 28 & NA \\
\hline 2015 Oct & 44 & 32 \\
\hline 2015 Nov & 33 & 24 \\
\hline 2015 Dec & 48 & 25 \\
\hline 2016 Jan & 50 & 28 \\
\hline 2016 Feb & 45 & 34 \\
\hline 2016 Mar & 64 & 46 \\
\hline 2016 Apr & 71 & 65 \\
\hline 2016 May & 56 & 57 \\
\hline 2016 Jun & 45 & 25 \\
\hline $2016 \mathrm{Jul}$ & 33 & 26 \\
\hline 2016 Aug & 34 & 34 \\
\hline 2016 Sep & 37 & 32 \\
\hline 2016 Oct & 38 & 40 \\
\hline 2016 Nov & 52 & 47 \\
\hline 2016 Dec & 48 & 37 \\
\hline 2017 Jan & 53 & 46 \\
\hline 2017 Feb & 46 & 43 \\
\hline 2017 Mar & 60 & 54 \\
\hline 2017 Apr & 56 & 53 \\
\hline 2017 May & 63 & 53 \\
\hline 2017 Jun & 41 & 33 \\
\hline $2017 \mathrm{Jul}$ & 33 & 30 \\
\hline 2017 Aug & 21 & 23 \\
\hline 2017 Sep & 32 & 33 \\
\hline
\end{tabular}




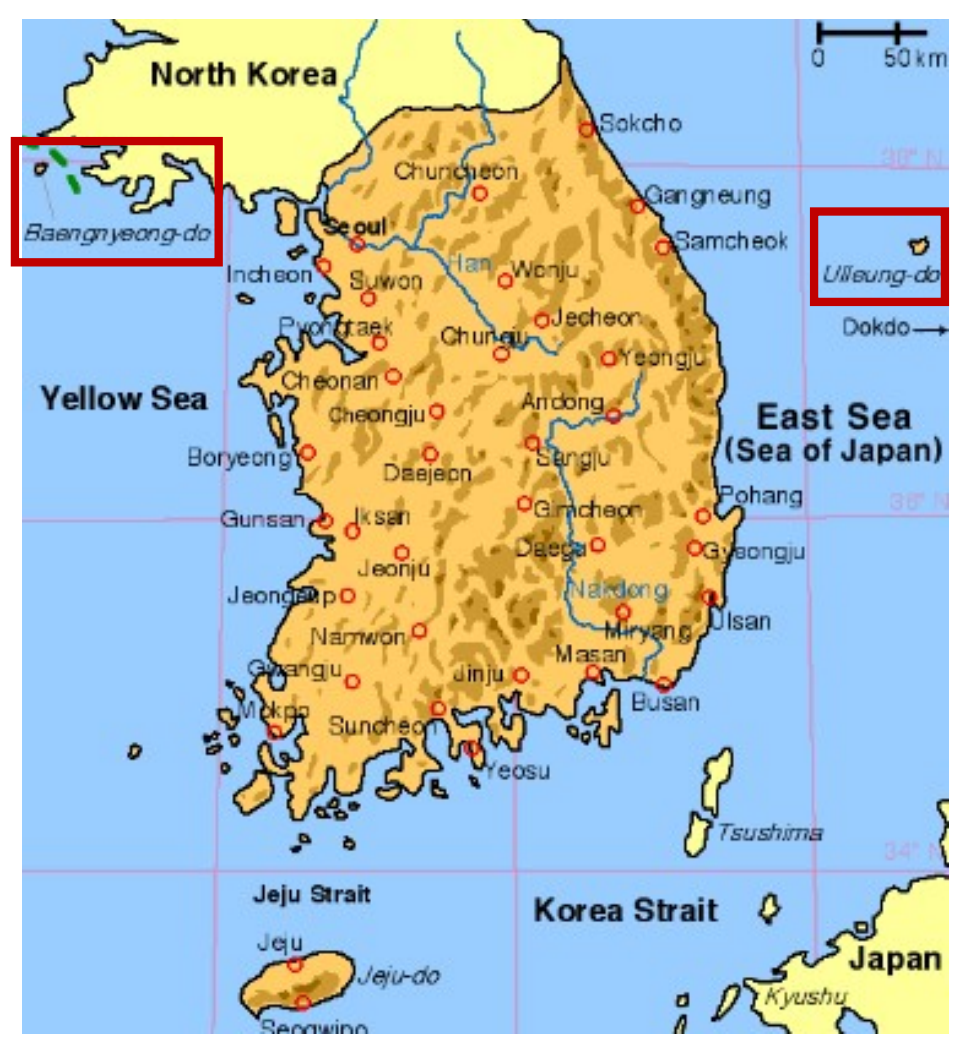

Figure A1. Location of Baekryeong-do and Ullreung-do [28]

\section{References}

1. Zhang, Q.,; Jiang, X.,; Tong, D.,; Davis, Steven J.,; Zhao, H.,; Geng, G.,; Feng, T.,; Zheng, B.; Lu, Zifeng,; G, David,; Ruijing Ni S.,; Brauer, M.,; van Donkelaar, A.,; Huo, H.; Liu, Zhu; Pan, Da; Kan, H.; Yan, Y.; Lin, J.; He, K.; Guan, D.; Transboundary health impacts of transported global air pollution and international trade, Nature, 2017, 543, pp. 705-709, (30 March 2017)

2. The Financial Times, South Korea joins ranks of world's most polluted countries, March 29, 2017.

3. OECD (The Organization for Economic Cooperation and Development) report, The economic consequences of outdoor air pollution, June 09, 2016

4. Ximhuanet report, China, Available online: http://www.xinhuanet.com/

5. CNBC news, South Korea's capital has unveiled emergency measures to combat a thick layer of smog coating the city, Available online:

https://www.cnbc.com/2018/01/15/smog-coated-south-korea-declares-pollution-emergency.html

6. Korea Times, 2018, More fine dust warnings issued this year: data, Available online: http://www.koreatimes.co.kr/www/nation/2018/04/113 247019.html

7. Garda World, 2018, South Korea: High levels of fine dust pollution March 26, Available online: https://www.garda.com/crisis24/news-alerts/103456/south-korea-high-levels-of-fine-dust-pollution-m arch-26

8. Garda World, 2018, South Korea increase in fine dust warnings for central regions in 2018, 
Available online:

https://www.garda.com/crisis24/news-alerts/108036/south-korea-increase-in-fine-dust-warnings-for-c entral-regions-in-2018

9. US Steering Group,; Korea Steering Group, NASA contributions to KORUS-AQ: An international cooperative air quality field study in Korea, 2017, white paper in NASA (National Aeronautics and Space Administration), Available online: https://www-air.larc.nasa.gov/missions/korus-aq/docs/White paper NASA KORUS-AQ.pdf

10. Earth Science Project Office Report, 2016, NASA, Introduction to the KORUS-AQ Rapid Science Synthesis Report, Available online: https://espo.nasa.gov/sites/default/files/documents/KORUS-AQ\%20RSSR.pdf

11. Cole S., Rink C., NASA Partners on Air Quality Study in East Asia, Feb, 2016, Available online: https://www.nasa.gov/press-release/nasa-partners-on-air-quality-study-in-east-asia

12. Cole S., Rink C., Early Airborne Results Address South Korean Air Quality, July, 2017

13. Arirang news, Republic of Korea, Korea's ozone concentration forecast to be as bad as last year's level, the worst in decade, 2017, Available online:

http://www.arirang.com/News/News View.asp?nSeq=206282

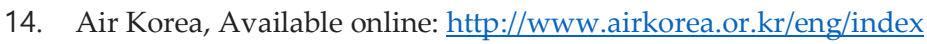

15. CNN news, Record-breaking temperatures leave 29 dead in South Korean heatwave, Aug, 3, 2018, Available online: https://edition.cnn.com/2018/08/02/asia/south-korea-heatwave-deaths-intl/index.html

16. Xinhua news, S. Korea's temperature hits all-time high of 40.7 on summer heat wave, Available online: http://www.xinhuanet.com/english/2018-08/01/c 137361557.htm

17. Baengnyeongdo, Wikipedia, Available online: https://en.wikipedia.org/wiki/Baengnyeongdo

18. Chung, A., Korea policy toward pollution and fine article: a sense of urgency, Korea Analysis $n$ 2, 2014, Available online: https://core.ac.uk/download/pdf/51180071.pdf

19. Boris, A.J., Lee, T., Park T., Choi, J., Seo, J., Collett Jr, J.L., Fog composition at Baengnyeong Island in the eastern Yellow Sea: detecting markers of aqueous atmospheric oxidations, 2018 Available online:

https://www.researchgate.net/publication/303733458_Fog_composition_at_Baengnyeong_Isand_in_th e eastern Yellow Sea Detecting markers of aqueous atmospheric oxidations

20. Chang, S.H.; Lee, S.; Evaluating fine dust pollution in Republic of Korea by statistical reasoning, and its applications, presented at 10 International Conference on Business, Economics and Social Sciences, 24-25, April 2018; The Jayakarta Lombok Resort, Lombok, Indonesia, 2018.

21. Particulate, Wikipedia Available online: https://en.wikipedia.org/wiki/Particulates

22. Sternberg T., Edwards M., Desert dust and health: a central asian review and steppe case study, International Journal of Environment Research and Public Health, 2017, November 14(11),

23. Karagulian F., Belis A C., Francisco C.C., Annette M. D., Sophie P., Heather B., Adair-Rohani, A., Contributions to citis' ambient particulate matter (PM): A systematic review of local source contributions at global level, Atmospheric Environment, Vol. 120, November 2015, pp. 475-483.

24. NASA, NASA Partners on Air Quality Study in East Asia, 2017 Available online: https://visibleearth.nasa.gov/view.php?id=58069

25. Ozone, Wikipedia Available online: https://en.wikipedia.org/wiki/Ozone

26. Global warming, Wikipedia Available online: https://en.wikipedia.org/wiki/Global warming

27. Atmospheric environment report in Republic of Korea, 2015-2018, Available online: http://www.me.go.kr/home/web/index.do?menuId=123 
28. Ulleungdo, Wikipedia, Available online: https://en.wikipedia.org/wiki/Ulleungdo

29. Korean Statistical Information service (KOSIS), Available online: http://kosis.kr/statHtml/statHtml.do?orgId=106\&tblId=DT_106N_03_0200076\&conn_path=I3

30. Chang, S.H. Summary Note for Management Statistics \& Data Interpretations, G-World Publisher Corp. (in Korean), Republic of Korea, 2018

31. NASA earth observatory, Temporary drought or permanent desert?, Available online: https://earthobservatory.nasa.gov/Features/Desertification/desertification2.php

32. Greenpeace forest solutions, Available online: https://www.greenpeace.org/archive-international/en/campaigns/forests/solutions/

33. Deforestation, Wikipedia Available online: https://www.worldwildlife.org/threats/deforestation

34. Sustainable energy, Wikipedia Available online: https://en.wikipedia.org/wiki/Sustainable energy

35. NASA top stories, Easing off the greenhouse gas, Available at: https://science.nasa.gov/science-news/science-at-nasa/2002/15jan_greenhouse, Jan, 15, 2002.

36. Sussman, R.; Gifford, R.; Abrahamse, W. Social Mobilization: How to Encourage Action on Climate Change. Pacific Institute for Climate Solutions, 2016. Available online: http://pics.uvic.ca/research-pages/publications/white-paper/social-mobilization-how-encourage-actio n-climate-change (accessed on 25 April 2018).

37. McKenzie-Moir, D.; Smith, W. Fostering Sustainable Behavior: An Introduction to Community-Based Social Marketing; New Society Publishers: Gabriola Island, BC, Canada, 1999

38. NASA top stories, responding to climate change, Available at: https://climate.nasa.gov/solutions/adaptation-mitigation/

39. NASA News, Rasmussen, C., Ramsayer, K., Seven case studies in carbon and climate, Available at https://climate.nasa.gov/news/2365/seven-case-studies-in-carbon-and-climate/ November 11, 2015

40. Coronato, H., Eco-friendly families, Penguin Group (USA) Inc, 375 Hudson Street, NY, USA, 2008.

41. Regional cooperation for the sustainable development and management in Northeast Asia, Choi Y.(ed.), Sustainable Asia Conference Papers, July 23, 2018. 